\title{
Large Strain With Ultra-Low Hysteresis and Enhanced Energy Storage Performance of Mn- Doped 0.65Bi0.5Na0.5Ti03-0.35SrTiO3 Lead-Free Ceramics
}

\author{
W.P. Cao ( $\nabla$ xiao5460hu@126.com ) \\ Harbin University of Commerce \\ Weili Li \\ Harbin Institute of Technology \\ Wenzhong Zhang \\ Harbin Institute of Technology \\ Dan Xu \\ Harbin University of Science and Technology \\ Jie Sheng \\ Harbin Institute of Technology
}

\section{Research Article}

Keywords: NBT-based ceramics, defect dipoles, electric-field induced strain, energy storage properties, electrostrictive effect

Posted Date: February 12th, 2021

DOl: https://doi.org/10.21203/rs.3.rs-184913/v1

License: (c) (i) This work is licensed under a Creative Commons Attribution 4.0 International License.

Read Full License 


\title{
Large strain with ultra-low hysteresis and enhanced energy storage performance of Mn-doped $\mathrm{0.65Bi}_{0.5} \mathrm{Na}_{0.5} \mathrm{TiO}_{3}-\mathrm{O}_{\text {.35 }} \mathrm{Sr}^{\mathrm{TiO}} \mathrm{O}_{3}$ lead-free ceramics
}

\author{
Wenping $\mathrm{Cao}^{\mathrm{a} *}$, Weili Li ${ }^{\mathrm{b}}$, Wenzhong Zhang ${ }^{\mathrm{b}}$, Dan $\mathrm{Xu}^{\mathrm{c}}$, Jie Sheng ${ }^{\mathrm{d}}$ \\ ${ }^{a}$ School of Light Industry, Harbin University of Commerce, Harbin 150028, P. R. China \\ ${ }^{b}$ School of Materials Science and Engineering, Harbin Institute of Technology, Harbin 150001, P. \\ R. China. \\ ${ }^{c}$ The Key Laboratory of Quantum Manipulation \& Control of Heilongjiang Province, Harbin \\ University of Science and Technology, Harbin 150080, P.R. China \\ ${ }^{d}$ Laboratory for Space Environment and Physical Science, Research Center of Basic Space \\ Science, Harbin Institute of Technology, Harbin 150001, PR China
}

\begin{abstract}
In this paper, the electric-field-induced strain behavior and energy storage performance of MnO-doped $0.65 \mathrm{Bi}_{0.5} \mathrm{Na}_{0.5} \mathrm{TiO}_{3}-0.35 \mathrm{SrTiO}_{3}(\mathrm{NBT}-\mathrm{ST}-x \mathrm{Mn})$ lead-free ceramics has been investigated. After the introduction of MnO into NBT-ST ceramics, pinched and double $P-E$ hysteresis loops with high $P_{\max }$ and negligible $P_{\mathrm{r}}$ can be observed due to the introduction of defect dipoles. As a result, a relatively high strain of $0.22 \%$ with ultra-low hysteresis of $14 \%$ was achieved under a moderate electric field of $60 \mathrm{kV} / \mathrm{cm}$ at $x=1.0 \mathrm{~mol} . \%$. Excellent energy storage performance of 1.14 and $1.17 \mathrm{~J} \mathrm{~cm}^{-3}$ with a high $\eta$ of 83 and $80 \%$ are achieved at $x=0.5$ and $1.0 \mathrm{~mol} . \%$, respectively. Meanwhile, high electrostriction coeffcient of $0.022 \mathrm{~m}^{4} \mathrm{C}^{2}$ with pure electrostrictive characteristics was obtained at $x=0.5 \mathrm{~mol} . \%$. The results illustrate that the proper selection of base composition and effective chemical modifier can made the NBT-ST an outstanding candidate for actuators and energy storage devices.
\end{abstract}

Keywords: NBT-based ceramics; defect dipoles; electric-field induced strain; energy storage properties; electrostrictive effect

\footnotetext{
${ }^{*}$ Corresponding author: School of Light Industry, Harbin University of Commerce, Harbin 150028, P. R. China E-mail addresses: xiao5460hu@126.com (W.P. Cao)
} 


\section{Introduction}

Piezoelectric ceramics are widely applied in industrial devices such as actuators, sensors and energy storage capacitors because of their excellent electromechanical properties [1-8]. Currently, the lead-based systems, such as $\mathrm{Pb}(\mathrm{Zr}, \mathrm{Ti}) \mathrm{O}_{3}$ (PZT) still dominated the global piezoelectric ceramics market due to their outstanding piezoelectric properties and thermal stability $[1,6]$. However, lead-based materials contain much lead oxide, which is harm to the environment and human beings. Therefore, it is very necessary to seek lead-free ceramics with excellent performance to replace lead-containing materials.

Among reported lead-free ceramic systems, $\mathrm{Na}_{0.5} \mathrm{Bi}_{0.5} \mathrm{TiO}_{3}$ (abbreviated as NBT)-based ceramics present giant electric-field induced strain [9-22], which makes NBT-based ceramics to be one of the most promising candidates to replace lead-containing materials. For example, large electric-field-induced strain value of $0.45 \%$ was achieved in $\mathrm{Na}_{0.5} \mathrm{Bi}_{0.5} \mathrm{TiO}_{3}-\mathrm{BaTiO}_{3}-\mathrm{K}_{0.5} \mathrm{Na}_{0.5} \mathrm{NbO}_{3}$ (NBT-BT-KNN) ceramic [10]. Liu et al. [13] found that the introduction of $\mathrm{Nb}$ into the $\mathrm{Na}_{0.5} \mathrm{Bi}_{0.5} \mathrm{TiO}_{3}-\mathrm{K}_{0.5} \mathrm{Bi}_{0.5} \mathrm{TiO}_{3}-\mathrm{SrTiO}_{3}(\mathrm{NBT}-\mathrm{KBT}-\mathrm{ST})$ system could induce a giant strain as high as $0.70 \%$. The obtained large strain in NBT-based ceramics is usually attributed to the ferroelectric to relaxor phase transition induced by external electric field. Although a high strain could be obtained in BNT-based ceramics, their strain loops show serious hysteresis behavior (> 50\%) with a strong nonlinearity. Therefore, how to reduce the hysteresis of NBT-based materials is a great challenge for the applications in high precision positioning devices and other actuators.

In recent years, some efforts have been devoted to reduce the hysteresis of NBT-based materials [23-34]. Ullah et al. [23] tailored the hysteresis behavior as low as $40 \%$ in Nb-doped NBT-KBT-Ba ${ }_{0.7} \mathrm{Sr}_{0.3} \mathrm{TiO}_{3}$ (BNT-BKT-BST) ceramic. Li et al. [25] found the introduction of A-site vacancies $\left(\mathrm{V}_{\mathrm{A}}\right)$ and oxygen vacancies $\left(\mathrm{V}_{\mathrm{O}}\right)$ into NBT-KBT-Sr $0.8 \mathrm{Bi}_{0.1} \square_{0.1} \mathrm{Ti}_{0.8} \mathrm{Zr}_{0.2} \mathrm{O}_{2.95}$ system could be beneficial for the reduction of strain hysteresis. The design of ceramic/ceramic composite consisting of an ergodic relaxor (matrix) and a nonergodic or ferroelectric phase (seed) was also identified as 
typical feature that could reduce the strain hysteresis [28-30]. In our previous work, both of the strain value and the hysteresis of NBT-BT-ST and NBT-ST systems could be improved simultaneously by the introducing of defect dipoles [26,34]. High strain of $0.24 \%$ under $80 \mathrm{kV} / \mathrm{cm}$ with ultra-low hysteresis (about 10\%) was obtained in Mn-doped NBT-BT-ST system while large strain of $0.32 \%$ with small hysteresis of $28 \%$ was realized at $60 \mathrm{kV} / \mathrm{cm}$ in Mn-doped 0.7NBT-0.3ST system. However, the applied electric field in Mn-doped NBT-BT-ST system was too high and the strain hysteresis in Mn-doped 0.7NBT-0.3ST system was still not small enough. It is well-known that both the proper selection of base composition and effective chemical modifier doping are important to obtain excellent strain properties. Here, in order to obtain large strain under low electric field meanwhile maintain ultra-low hysteresis, we selected 0.65 NBT-0.35ST ceramic as base composition which exhibits slimmer $P$ - $E$ loops than 0.7NBT-0.3ST ceramic, and doped with different content of $\mathrm{MnO}$ to achieve optimized strain properties. Meanwhile, the energy storage properties of Mn-doped 0.65NBT-0.35ST ceramic can also be enhanced due to the combined contribution of high electric breakdown feld (BDS) and $P_{\max }-P_{\mathrm{r}}$ value. The influence of $\mathrm{MnO}$ enhancement on electric-field-induced strain and energy storage density of 0.65NBT-0.35ST ceramics were studied in details.

\section{Experimental}

$0.65 \mathrm{Na}_{0.5} \mathrm{Bi}_{0.5} \mathrm{TiO}_{3}-0.35 \mathrm{SrTiO}_{3}$ ceramics doped with $0,0.5,1$ and $1.5 \mathrm{~mol}$. \% $\mathrm{MnO}$ (denoted as NBT-ST- $x \mathrm{Mn}$ ) were prepared using a conventional solid-state reaction method. The raw materials of this experiment were $\mathrm{Na}_{2} \mathrm{CO}_{3}(99.8 \%)$, $\mathrm{Bi}_{2} \mathrm{O}_{3}(99.9 \%), \mathrm{MnO}(99.5 \%), \mathrm{SrCO}_{3}(99.95 \%)$ and $\mathrm{TiO}_{2}(99.9 \%)$. The details of sample preparation are reported elsewhere [26].

The crystal structure of sintered ceramics was analyzed using X-ray diffraction (XRD) on a Philips X'Pert diffractometer with $\mathrm{Cu}$ Ka radiation. The surface microstructure of the samples was observed with a scanning electron microscopy (SEM, Quanta 600F). Before electrical performance characterization, all samples were carefully ground to smooth and flat on both sides. Silver paste was first 
uniformly painted onto both surfaces of each sample, and then insulated at $600^{\circ} \mathrm{C}$ for $40 \mathrm{~min}$ to form electrodes. The dielectric constant and dielectric loss as a function of temperature $\left(30-400^{\circ} \mathrm{C}\right)$ were carried out using an Agilent 4294A precision impedance analyzer with the discrete frequencies: $1 \mathrm{kHz}, 10 \mathrm{kHz}$ and $100 \mathrm{kHz}$. Ferroelectric hysteresis loops $(P-E)$ and electrostrain curves $(S-E)$ were measured using a Radiant Technologies Precision II (Radiant Tech.USA) in a silicone oil bath.

\section{Results and discussion}

X-ray diffraction patterns of the NBT-ST- $x$ Mn ceramics are displayed in Fig. 1. As shown in Fig. 1(a), all samples exhibited a single phase perovskite structure without apparent secondary phases, which proved that the $\mathrm{MnO}$ had completely incorporated into the structure of the $0.65 \mathrm{NBT}-0.35 \mathrm{ST}$ ceramics. The characterization of (200) peaks of the four samples was investigated in detail to obtain the phase structure evolution, as shown in Fig. 1(b). Obvious splitting of (002) and (200) peaks were detected between $44^{\circ}$ and $48^{\circ}$ for all the samples, indicating a tetragonal distortion of the pseudocubic lattice.

Fig. 2 shows the surface microstructure images (SEM) of NBT-ST- $x$ Mn ceramics with different Mn doping levers. Nearly no pores were observed on the images of all the samples, suggesting that the ceramics were densely sintered. For the sample with $x=0.0 \mathrm{~mol} . \%$, the average grain size is about $2 \mu \mathrm{m}$. After doping with a slight amount of $\mathrm{MnO}$, the grain size increases obviously, and both of the large and small grains can be observed in the same sample. With the further increase of $x$, the grains further grow up and the proportion of large ones obviously increase. The maximum grain size can reach to about $20 \mu \mathrm{m}$ at $x=1.5 \mathrm{~mol} \%$. The increased grain size by doping $\mathrm{MnO}$ in NBT-based ceramics has also been observed in our previous research [26, 34].

The dielectric constant $\left(\varepsilon_{\mathrm{r}}\right)$ and dielectric loss tangent $(\tan \delta)$ as a function of temperature for NBT-ST- $x$ Mn ceramics measured at 1,10 and $100 \mathrm{kHz}$ are displayed in Fig.3 (a)-(d). As $\varepsilon_{\mathrm{r}}-T$ curves shown, one distinctive dielectric anomaly with a strong frequency-dependent dispersion at a lower temperature and a relatively weak frequency-dependent dispersion at a higher temperature are observed for all the 
samples. One distinctive dielectric anomaly observed in $\varepsilon_{\mathrm{r}}-T$ curves proved that the phase structure is the $T$ phase at room temperature, which is in accordance with the XRD analysis. The temperature at which the $\varepsilon_{\mathrm{r}}$ reaches its maximum value is assigned to the curie temperature $T_{\mathrm{m}}$, which corresponds to the phase transition from the relaxation phase to the paraelectric phase [35]. With $x$ increasing, the $T_{\mathrm{m}}(1 \mathrm{kHz})$ increases obviously while the maximum value of $\varepsilon_{\mathrm{r}}$ enhances firstly and then have some decrease, as shown in Fig.3 (e). The enhanced $T_{\mathrm{m}}$ is beneficial for the temperature stability of strains. Moreover, all the samples exhibit broadness peaks at $T_{\mathrm{m}}$, suggesting a relaxor behavior in these ceramics.

For relaxor ferroelectrics, the diffuseness in the phase transition can be described by the following equation [36]

$$
1 / \varepsilon_{\mathrm{r}}-1 / \varepsilon_{\max }=C^{-\gamma}\left(T-T_{\max }\right)
$$

where $C$ is the Curie-like coefficient and $\gamma$ is the degree of relaxation ranging between 1 for a normal ferroelectric and 2 for an ideal relaxor ferroelectric. The plots of $\ln \left(1 / \varepsilon_{\mathrm{r}}-1 / \varepsilon_{\max }\right)$ versus $\ln \left(T-T_{\max }\right)$ for NBT-ST- $x$ Mn ceramics are shown in Fig. 3 (f). According to the equation (1), the calculated values of $\gamma$ have an obvious increase after doping $\mathrm{MnO}$. The increase of $\gamma$ is attributed to that the adding of $\mathrm{Mn}^{2+}$ ions $(0.067 \mathrm{~nm})$ would occupy $\mathrm{Ti}^{4+}(0.0605 \mathrm{~nm})$ sites due to the similarity in ionic radius, which means the $\mathrm{B}$ position is occupied by two kinds of ions after doping $\mathrm{MnO}$. Accordingly, the composition and structure of NBT-ST- $x$ Mn ceramics is inevitably to be fluctuated, leading to the increase of $\gamma$ values. Schütz et al. [37] reported that relaxor behavior would be conducive to trigger a giant strain. Thus, the increase of $\gamma$ values induced by the addition of Mn ions may be beneficial to obtain large strain.

Fig. 4 exhibits the bipolar P-E hysteresis loops and $S-E$ curves of NBT-ST- $x$ Mn ceramics measured at $10 \mathrm{~Hz}$ under an electric feld of $60 \mathrm{kV} / \mathrm{cm}$. Comparing with unmodified $0.65 \mathrm{NBT}-0.35 \mathrm{ST}$ ceramic, the maximum polarization $\left(P_{\max }\right)$ enhances obviously while the remanent polarization $\left(P_{\mathrm{r}}\right)$ and coercive field $\left(E_{\mathrm{c}}\right)$ decrease in varying extent after doping $\mathrm{MnO}$. The $P_{\max }$ value can be enhanced to $34 \mu \mathrm{C} / \mathrm{cm}^{2}$ while the $P_{\mathrm{r}}$ value is only $2.8 \mu \mathrm{C} / \mathrm{cm}^{2}$ under $60 \mathrm{kV} / \mathrm{cm}$ at $x=1.0 \mathrm{~mol} . \%$. The obviously decrease of $P_{\mathrm{r}}$ clearly demonstrated that the defect dipoles also exist in Mn-doped 
0.65NBT-0.35ST ceramics. The associated defect dipole moment $\left(P_{\mathrm{D}}\right)$ can act as an internal field to switch the new domain back to its original state after removing the electric field, leading to the pinched and double $P$-E hysteresis loops with large $P_{\max }$ and small $P_{\mathrm{r}}[38,39]$. As the $S-E$ curves shown, there is almost no negative strain can be seen for all the samples, which is the typical piezoelectric response for relaxor ferroelectric materials.

From the application point of view, low hysteresis $(H)$ is as important as strain values. The strain values $S$ and hysteresis $H\left(H=\triangle S / S_{\max }, \triangle S\right.$ and $S_{\max }$ are measured at $E_{\max } / 2$ and $E_{\max }$, respectively) as a function of doping content for NBT-ST- $x \mathrm{Mn}$ ceramics are displayed in Fig.5. With the increase of $\mathrm{MnO}$ doping, the strain increases firstly and then has a slight decrease while the hysteresis decreases firstly and then has some increase. The maximum value of strain can be up to $0.22 \%$ at $60 \mathrm{kV} / \mathrm{cm}$ with ultra-low hysteresis of $14 \%$ when $1.0 \mathrm{~mol} \% \mathrm{MnO}$ is doped. The improvement of strain values for NBT-ST- $x$ Mn ceramics is attributed to the introduction of defect dipoles, the enhancement of relaxor behavior and the increased grain size [13, 40]. This result illustrates that the appropriate addition of $\mathrm{MnO}$ in 0.65NBT-0.35ST ceramic could not only enhance the maximum achievable strain value but also decrease the hysteresis.

In order to clearly compare the actuation properties of NBT-based materials, data from previous literatures that devoted to reduce the hysteresis are listed in Table 1. Obviously, the hysteresis of NBT-based ceramics is still more than $20 \%$ by doping with effective chemical modifiers or designing ceramic/ceramic composites, and small hysteresis (10-20\%) could be obtained only by optimizing the preceding techniques, such as texture control or using spark plasma sintering (SPS) method. Here, a relatively high strain of $0.22 \%$ with ultra-low hysteresis of $14 \%$ are achieved simultaneously at $60 \mathrm{kV} / \mathrm{cm}$ by doping $\mathrm{MnO}$ into $0.65-\mathrm{NBT}-0.35 \mathrm{ST}$ ceramics. The result illustrates that the proper selection of base composition and effective chemical modifier can obtain large strain under low electric field meanwhile maintain ultra-low hysteresis. 
Table 1 Comparison of electro-strain $S$, strain hysteresis $H$ and $E_{\max }$ values of NBT-based ceramics

\begin{tabular}{lllll}
\hline Material & $S(\%)$ & $H(\%)$ & $E_{\max }(\mathrm{kV} / \mathrm{cm})$ & Ref. \\
\hline NBT-KBT-BST-2\%Nb & 0.38 & 40 & 60 & {$[23]$} \\
NBT-KBT-2\%BZT & 0.32 & 40 & 65 & {$[24]$} \\
NBT-KBT-6\%SBZT & 0.72 & 36 & 110 & {$[25]$} \\
0.70NBT-0.30ST-0.5\%Mn & 0.32 & 28 & 60 & {$[26]$} \\
NBT-KBT-2\%BCZ & 0.30 & 25 & 55 & {$[27]$} \\
BNT-BT-10KNN & 0.16 & 25 & 80 & {$[31]$} \\
NBT-KBT-4\%BA & 0.21 & 24 & 70 & {$[32]$} \\
NBT-KBT- Bi4Ti3 ${ }_{12}$ & 0.29 & 23 & 60 & {$[33]$} \\
NBT-BT-ST-1.1\%Mn & 0.24 & 10 & 80 & {$[34]$} \\
BNT-BT-2.5\%LN $($ SPS $)$ & 0.64 & 19.5 & 50 & {$[17]$} \\
Textured KBT-BT-NBT & 0.48 & 17 & 130 & {$[41]$} \\
0.65NBT-0.35ST-1.0\%Mn & 0.22 & 14 & 60 & This work \\
\hline
\end{tabular}

Large strain with ultra-low hysteresis is beneficial to obtain purely electrostrictive effect. Fig. 6 presents the $S$ - $P^{2}$ plots derived from the corresponding polarization and strain hysteresis loops of NBT-ST- $x$ Mn ceramics. The electrostrictive effect can be calculated by the formula: $S=Q_{33} P^{2}$, where $S, Q_{33}$, and $P$ are the strain, electrostrictive coefficient, and polarization, respectively [26]. The hysteresis has made the $S$ - $P^{2}$ curve deviate slightly from a quadratic relationship at $x=0.0 \%$ and $x=1.5 \%$. For $0.5 \%$ and $1.0 \%$ Mn-doped ceramics, a pretty linear dependence of strain on polarization square can be noted, classifying that "purely" electrostrictive effects are achieved. The calculated $Q_{33}$ value for $0.5 \%$ Mn-doped NBT-ST ceramic is $0.022 \mathrm{~m}^{4} / \mathrm{C}^{2}$, which is no smaller than that of the representative electrostrictive materials in the literature $[24,26,31,34]$.

Except for the high strain with ultra-low hysteresis, Mn doping also contribute to enhance the energy storage density of $0.65 \mathrm{NBT}-0.35 \mathrm{ST}$ ceramics. Generally, energy-storage density of nonlinear dielectric ceramics can be calculated by the unipolar $P-E$ loop with the following equations: [42] 


$$
\begin{gathered}
W_{\text {rec }}=\int_{P_{r}}^{P_{\max }} E d P \\
\eta=\frac{W_{\text {rec }}}{W_{\text {rec }}+W_{\text {loss }}} \times 100 \%
\end{gathered}
$$

where $W_{\text {rec }}, W_{\text {loss }}$ and $\eta$ denote the recoverable energy storage density, energy loss density and energy storage efficiency, respectively. It can be seen from the above equations that large $P_{\max }$, small $P_{\mathrm{r}}$ and high BDS is very important to achieve high energy storage density. In order to investigate the electric-field-strength dependence on the energy storage, the unipolar $P-E$ loops of the NBT-ST- $x$ Mn ceramics samples measured in the electric field ranging from 10 to $70 \mathrm{kVcm}^{-1}$ at room temperature are shown in Fig.7. Similar to the bipolar $P-E$ loops, the obtained unipolar $P-E$ loops become slimmer after doping with $\mathrm{MnO}$. Additionally, compared with the unmodified 0.65 NBT- $0.35 \mathrm{ST}$ ceramic, the $P_{\max }$ increases significantly while $P_{\mathrm{r}}$ decreases in varying extent, and the Mn-doped samples always maintain low $P_{\mathrm{r}}$ with different electric fields due to the introduction of defect dipoles. Thus, the energy storage properties of NBT-based ceramics could be improved by the addition of $\mathrm{MnO}$.

Based on equations (2)-(3) and obtained unipolar P-E loops of Fig.7(a)-(d), the calculated $W_{\text {rec }}, \mathrm{W}_{\text {loss }}$ and $\eta$ of the NBT-ST- $x$ Mn ceramics are presented in Fig.8. The $W_{\text {rec }}$ and $\mathrm{W}_{\text {loss }}$ of all the samples increase by different degrees with increasing applied electric field. Noteworthily, after introducing MnO into the 0.65NBT-0.35ST ceramic, the $W_{\text {rec }}$ values improve obviously due to the enhanced $P_{\max }$ and reduced $P_{\mathrm{r}}$. The maximum $W_{\text {rec }}$ value for the NBT-ST- $x$ Mn ceramics increase to as high as $0.92 \mathrm{~J} \mathrm{~cm}^{-3}$ at $70 \mathrm{kV} / \mathrm{cm}$ for $x=1.0 \mathrm{~mol} \%$. Meanwhile, the $\mathrm{W}_{\text {loss }}$ values of Mn-doped samples decrease to some certain degree at high electric field due to the result that shape of $P-E$ loops changes from fat to pinched, leading to the enhancement of $\eta$ (shown in the inset of Fig.8 (a)). The $\eta$ values increase from $64 \%$ for $x=0.0$ mol. $\%$ to $81 \%, 78 \%$ and $73 \%$ at $x=0.5,1.0$ and $1.5 \mathrm{~mol} \%$, respectively. These results illustrate that the addition of $\mathrm{MnO}$ could boost the energy storage property of $0.65 \mathrm{NBT}-0.35 \mathrm{ST}$ solid solution effectively.

In addition, the BDS is also a very important parameter for energy storage ceramics. Thus, the BDS of NBT-ST- $x$ Mn ceramics was also analyzed by Weibull 
distribution [26,43], as shown in Fig. 9(a). The average BDS is determined by fitting lines and the results are displayed in the inset of Fig. 9(a). It can be found that all the samples fit well with the Weibull distribution function. The BDS of NBT-ST- $x \mathrm{Mn}$ ceramics can be enhanced with MnO doping, and the BDS values are 74, 89, 83 and $80 \mathrm{kV} / \mathrm{cm}$ for 0.0-1.5 mol.\% Mn-doped ceramics, respectively. Previous researches revealed that the addition of 'hard' dopant (Fe, Mn, etc.) is believed to be an effective method to improve BDS $[44,45]$.The enhancement of BDS for NBT-ST- $x$ Mn ceramics may be caused by the 'hard' dopant. Fig. 9(b) presents unipolar P-E loops of the NBT-ST- $x$ Mn ceramics measured at their critical BDS. Clearly, large $P_{\max }$ and small $P_{\text {r }}$ can be obtained simultaneously after doping MnO into 0.65NBT-0.35ST ceramic. The difference between $P_{\max }$ and $P_{\mathrm{r}}\left(P_{\max }-P_{\mathrm{r}}\right)$ of the four samples are displayed in Fig. 9(c). It can be found that the $P_{\max }-P_{\mathrm{r}}$ value significantly enhanced by doping $\mathrm{MnO}$, and the values can be up to 35 and $37 \mu \mathrm{C} \mathrm{cm}^{-2}$ at $x=0.5$ and $1.0 \mathrm{~mol} \%$, respectively. Such high $P_{\max }-P_{\mathrm{r}}$ and BDS values are beneficial for obtaining high energy storage density and efficiency. Fig. 9(d) presents the calculated $W_{\text {rec}}, W_{\text {loss }}$ and $\eta$ of the NBT-ST- $x$ Mn ceramics. As expected, excellent energy storage performance of 1.14 and $1.17 \mathrm{~J} \mathrm{~cm}^{-3}$ with a high $\eta$ of 83 and $80 \%$ are achieved at $x=0.5$ and $1.0 \mathrm{~mol} . \%$, respectively. The obtained results indicate that with proper doping of $\mathrm{MnO}$ into the NBT-ST ceramics, high $W_{\text {rec }}$ and $\eta$ can be achieved simultaneously due to the enhanced BDS and $P_{\max }-P_{\mathrm{r}}$ value.

\section{Conclusions}

In conclusion, NBT-ST- $x \mathrm{Mn}$ lead-free ceramics were designed and prepared by solid state synthesis method. It has been found that the addition of $\mathrm{MnO}$ also can induce defect dipoles into $0.65 \mathrm{NBT}-0.35 \mathrm{ST}$ ceramic, which result in double $P-E$ hysteresis loops with high $P_{\max }$ and small $P_{\mathrm{r}}$. Accordingly, a relatively high strain of $0.22 \%$ with ultra-low hysteresis of $14 \%$ was achieved under a moderate electric field of $60 \mathrm{kV} / \mathrm{cm}$ at $x=1.0 \mathrm{~mol} \%$ due to the introduction of defect dipoles, the enhancement of relaxor behavior and the increased grain size. Excellent energy storage performance of 1.14 and $1.17 \mathrm{~J} \mathrm{~cm}^{-3}$ with a high $\eta$ of 83 and $80 \%$ were also 
achieved at $x=0.5$ and 1.0 mol.\% due to the enhanced BDS and $P_{\max }-P_{\mathrm{r}}$ value. Meanwhile, high electrostriction coeffcient of $0.022 \mathrm{~m}^{4} \mathrm{C}^{2}$ with pure electrostrictive characteristics was obtained at $x=0.5$ mol.\%. The findings demonstrate that MnO-doped NBT-based ceramics are promising to be applicable for actuators and energy storage devices.

\section{Acknowledgement}

This work was supported by the National Natural Science Foundation of China (No. 51802061, 51677033 and 51702069), University Nursing Program for Young Scholars with Creative Talents in Heilongjiang Province (No. UNPYSCT-2020215), Youth Innovative Talent Support Program of Harbin University of Commerce (No. 2020CX05), and Doctoral Start-up Scientific Research Foundation of Harbin University of Commerce (No. 2019DS078).

\section{References}

[1] Gubinyi Z, Batur C, Sayir A, et al. Electrical properties of PZT piezoelectric ceramics at high temperatures. J Electroceram 2007, 20: 95-105.

[2] Chen JG, Shi HD, Liu GX, et al. Temperature dependence of dielectric, piezoelectric and elastic properties of $\mathrm{BiScO}_{3}-\mathrm{PbTiO}_{3}$ high temperature ceramics with morphotropic phase boundary (MPB) composition. J Alloys Compd 2012, 537: 280-285.

[3] Li F, Jin L, Xu Z, et al. Electrostrictive effect in $\mathrm{Pb}\left(\mathrm{Mg}_{1 / 3} \mathrm{Nb}_{2 / 3}\right) \mathrm{O}_{3}-x \mathrm{PbTiO}_{3}$ crystals. Appl Phys Lett 2013, 102: 152910.

[4] Jia WX, Hou YD, Zheng MP, et al. Advances in lead-free high-temperature dielectric materials for ceramic capacitor application. IET Nanodielectr 2018, 1: 3-16.

[5] Li DX, Shen ZY, Li ZP, et al. P-E hysteresis loop going slim in $\mathrm{Ba}_{0.3} \mathrm{Sr}_{0.7} \mathrm{TiO}_{3}$-modified $\mathrm{Bi}_{0.5} \mathrm{Na}_{0.5} \mathrm{TiO}_{3}$ ceramics for energy storage applications. J Adv Ceram 2020, 9(2): 183-192.

[6] Jia H, Hu XK, Chen JG. Temperature-dependent piezoelectric strain and resonance performance of $\mathrm{Fe}_{2} \mathrm{O}_{3}$-modified $\mathrm{BiScO}_{3}-\mathrm{PbTiO}_{3}-\mathrm{Pb}\left(\mathrm{Nb}_{1 / 3} \mathrm{Mn}_{2 / 3}\right) \mathrm{O}_{3}$ ceramics. J Eur Ceram Soc 2019, 39: 2348-2353. 
[7] Xie H, Yang L, Pang SJ, et al.The evolution of phase structure, dielectric, strain, and energy storage density of complex-ions $\left(\mathrm{Sr}_{1 / 3} \mathrm{Nb}_{2 / 3}\right)^{4+}$ doped $0.82 \mathrm{Bi}_{0.5} \mathrm{Na}_{0.5} \mathrm{TiO}_{3}-0.18 \mathrm{Bi}_{0.5} \mathrm{~K}_{0.5} \mathrm{TiO}_{3}$ ceramics. J Phys Chem Solid 2019, 126: 287-293.

[8] Wang HX, Zhao PY, Chen LL, et al. Energy storage properties of $0.87 \mathrm{BaTiO}_{3}-0.13 \mathrm{Bi}\left(\mathrm{Zn}_{2 / 3}\left(\mathrm{Nb}_{0.85} \mathrm{Ta}_{0.15}\right)_{1 / 3}\right) \mathrm{O}_{3}$ multilayer ceramic capacitors with thin dielectric layers. J Adv Ceram 2020, 9(3): 292-302.

[9] Habib M, Munir M, Khan SA, et al. Evaluation of high strain response in lead-free BNBTFS-xNb ceramics by structure and ferroelectric characterizations. J Phys Chem Solid 2020, 138: 109230.

[10] Zhang ST, Kounga AB, Aulbach E, et al. Giant strain in lead-free piezoceramics $\mathrm{Bi}_{0.5} \mathrm{Na}_{0.5} \mathrm{TiO}_{3}-\mathrm{BaTiO}_{3}-\mathrm{K}_{0.5} \mathrm{Na}_{0.5} \mathrm{NbO}_{3}$ system. Appl Phys Lett 2007, 91(11): 112906.

[11] Hiruma Y, Imai Y, Watanabe $Y$, et al. Large electrostrain near the phase transition temperature of $\left(\mathrm{Bi}_{0.5} \mathrm{Na}_{0.5}\right) \mathrm{TiO}_{3}-\mathrm{SrTiO}_{3}$ ferroelectric ceramics. Appl Phys Lett 2008, 92: 262904.

[12] Jo W, Granzow T, Aulbach E, et al. Origin of the large strain response in $\left(\mathrm{K}_{0.5} \mathrm{Na}_{0.5}\right) \mathrm{NbO}_{3}$-modified $\left(\mathrm{Bi}_{0.5} \mathrm{Na}_{0.5}\right) \mathrm{TiO}_{3}-\mathrm{BaTiO}_{3}$ lead-free piezoceramics. J Appl Phys 2009, 105: 094102.

[13] Liu XM, Tan XL. Giant strains in non-textured $\left(\mathrm{Bi}_{1 / 2} \mathrm{Na}_{1 / 2}\right) \mathrm{TiO}_{3}$-based lead-free ceramics. $A d v$ Mater 2016, 28: 574-578.

[14] Hao J, $\mathrm{Xu}$ Z, Chu R, et al. Field-induced large strain in lead-free $\left(\mathrm{Bi}_{0.5} \mathrm{Na}_{0.5}\right)_{1-x} \mathrm{Ba}_{x} \mathrm{Ti}_{0.98}\left(\mathrm{Fe}_{0.5} \mathrm{Ta}_{0.5}\right)_{0.02} \mathrm{O}_{3}$ piezoelectric ceramics. J Alloy Comp 2016, 677: 96-104.

[15] Wang C, Li Q, Yadav AK, et al. $\mathrm{Bi}_{0.48}\left(\mathrm{Na}_{0.84} \mathrm{~K}_{0.16}\right)_{0.48} \mathrm{Sr}_{0.04}\left(\mathrm{Ti}_{1-x} \mathrm{Ta}_{x}\right) \mathrm{O}_{3}$ lead-free ceramics with enhanced electric field-induced strain. J Alloy Comp 2019, 803: 1082-1089.

[16] Zhang $\mathrm{HB}$, Ma WG, Xie B, et al. $\left(\mathrm{Na}_{1 / 2} \mathrm{Bi}_{1 / 2}\right) \mathrm{TiO}_{3}$-based lead-free co-fired multilayer actuators with large strain and high fatigue resistance. J Am Ceram Soc 2019, 102: 6147-6155.

[17] Chen J, Wang YP, Wu L, et al. Effect of nanocrystalline structures on the large strain of $\mathrm{LiNbO}_{3}$ doped $\left(\mathrm{Bi}_{0.5} \mathrm{Na}_{0.5}\right) \mathrm{TiO}_{3}-\mathrm{BaTiO}_{3}$ materials. J Alloys Comp 2019, 775: 865-871.

[18] Si Y, Li Y, Li L, et al. Giant electro-strain in textured $\mathrm{Li}^{+}$-doped 0.852BNT-0.11BKT-0.038BT ternary lead-free piezoelectric ceramics. J Am Ceram Soc 2019, 00: 1-8.

[19] Gong YY, He X, Chen C, et al. Large electric field-induced strain in ternary $\mathrm{Bi}_{0.5} \mathrm{Na}_{0.5} \mathrm{TiO}_{3}-\mathrm{BaTiO}_{3}-\mathrm{Sr}_{2} \mathrm{MnSbO}_{6}$ lead-free ceramics. Ceram Int 2019, 45: 7173-7179.

[20] Liu X, Xue SD, Wang FF, et al. Grain size dependent physical properties in lead-free 
multifunctional piezoceramics: A case study of NBT-xST system. Acta Mater 2019, 164: 12-24.

[21] Li L, Zhang J, Wang RX, et al. Thermally-stable large strain in $\mathrm{Bi}\left(\mathrm{Mn}_{0.5} \mathrm{Ti}_{0.5}\right) \mathrm{O}_{3}$ modifed $0.8 \mathrm{Bi}_{0.5} \mathrm{Na}_{0.5} \mathrm{TiO}_{3}-0.2 \mathrm{Bi}_{0.5} \mathrm{~K}_{0.5} \mathrm{TiO}_{3}$ ceramics. J Eur Ceram Soc 2019, 39: 1827-1836.

[22] Manotham S, Jaita P, Randorn C, et al. Excellent electric field-induced strain with high electrostrictive and energy storage performance properties observed in lead-free $\mathrm{Bi}_{0.5}\left(\mathrm{Na}_{0.84} \mathrm{~K}_{0.16}\right)_{0.5} \mathrm{TiO}_{3}-\mathrm{Ba}\left(\mathrm{Nb}_{0.01} \mathrm{Ti}_{0.99}\right) \mathrm{O}_{3}-\mathrm{BiFeO}_{3}$ ceramics. J Alloy Comp 2019, 808: 151655 .

[23] Ullah A, Malik RA, Ullah A, et al. Electric-field-induced phase transition and large strain in lead-free Nb-doped BNKT-BST ceramics. J Eur Ceram Soc 2014, 34: 29-35.

[24] Bai WF, Chen DQ, Huang YW, et al. Temperature-insensitive large strain response with a low hysteresis behavior in NBT-based ceramics. Ceram Int 2016, 42: 7669-7680.

[25] Li TY, Lou XJ, Ke XQ, et al. Giant strain with low hysteresis in A-site-deficient $\left(\mathrm{Bi}_{0.5} \mathrm{Na}_{0.5}\right)$ $\mathrm{TiO}_{3}$-based lead-free piezoceramics. Acta Mater 2017, 128: 337-344.

[26] Cao WP, Sheng J, Qiao YL, et al. Optimized strain with small hysteresis and high energy-storage density in Mn-doped NBT-ST system. J. Eur. Ceram. Soc. 39 (2019) 4046-4052.

[27] Lee $\mathrm{HB}$, Heo DJ, Malik RA, et al. Lead-free $\mathrm{Bi}_{1 / 2}\left(\mathrm{Na}_{0.82} \mathrm{~K}_{0.18}\right)_{1 / 2} \mathrm{TiO}_{3}$ ceramics exhibiting large strain with small hysteresis. Ceram Int 2013, 39: S705-S708.

[28] Khansur NH, Groh C, Jo W, et al. Tailoring of unipolar strain in lead-free piezoelectrics using the ceramic/ceramic composite approach. J Appl Phys 2014, 115: 124108.

[29] Groh C, Franzbach DJ, Jo W, et al. Relaxor/ferroelectric composites: a solution in the quest for practically viable lead-free incipient piezoceramics. Adv Funct Mater 2014, 24: 356-362.

[30] Zhang H, Groh C, Zhang Q, et al. Large strain in relaxor/ferroelectric composite lead-free piezoceramics. Adv Electron Mater 2015, 1: 1500018.

[31] Zhang ST, Kounga AB, Jo W, et al. High-strain lead-free antiferroelectric electrostrictors. Adv Mater 2009, 21: 4716-4721.

[32] Qian H, Yu ZL, Mao MM, et al. Nanoscale origins of small hysteresis and remnant strain in $\mathrm{Bi}_{0.5} \mathrm{Na}_{0.5} \mathrm{TiO}_{3}$-based lead-free ceramics. J Eur Ceram Soc 2017, 37: 3483-3491.

[33] Fan PY, Zhang YY, Zhang Q, et al. Large strain with low hysteresis in $\mathrm{Bi}_{4} \mathrm{Ti}_{3} \mathrm{O}_{12}$ modified $\mathrm{Bi}_{1 / 2}\left(\mathrm{Na}_{0.82} \mathrm{~K}_{0.18}\right)_{1 / 2} \mathrm{TiO}_{3}$ lead-free piezoceramics. J Eur Ceram Soc 2018, 38: 4404-4413.

[34] Cao WP, Li WL, Feng Y, et al. Defect dipole induced large recoverable strain and high energy-storage density in lead free $\mathrm{Na}_{0.5} \mathrm{Bi}_{0.5} \mathrm{TiO}_{3}$-based systems. Appl Phys Lett 2016, 108: 
202902.

[35] Cao WP, Li WL, Dai XF, et al. Large electrocaloric response and high energy-storage properties over a broad temperature range in lead-free NBT-ST ceramics. J Eur Ceram Soc 2016, 36: 593-600

[36] Malathi AR, Devi CS, Kumar GS, et al. Dielectric relaxation in NBT-ST ceramic composite materials. Ionics 2013, 19: 1751-1760.

[37] Schütz D, Deluca M, Krauss W, et al. Lone-Pair-Induced Covalency as the Cause of Temperatureand Field-Induced Instabilities in Bismuth Sodium Titanate. Adv Funct Mater 2012, 22: 2285-2294.

[38] Feng ZY, Ren X. Aging effect and large recoverable electrostrain in $\mathrm{Mn}$-doped $\mathrm{KNbO}_{3}$-based ferroelectrics. Appl Phys Lett 2007, 91: 032904.

[39] Zhang LX, Chen W, Ren X. Large recoverable electrostrain in Mn-doped ( $\mathrm{Ba}, \mathrm{Sr}) \mathrm{TiO}_{3}$ ceramics. Appl Phys Lett 85 (2004) 5658-5660.

[40] Li HL, Liu Q, Zhou JJ, et al. Grain size dependent electrostrain in $\mathrm{Bi}_{1 / 2} \mathrm{Na}_{1 / 2} \mathrm{TiO}_{3}-\mathrm{SrTiO}_{3}$ incipient piezoceramics. J Eur Ceram Soc 2016, 36: 2849-2853.

[41] Maurya D, Zhou Y, Wang Y, et al. Giant strain with ultra-low hysteresis and high temperature stability in grain oriented lead-free $\mathrm{K}_{0.5} \mathrm{Bi}_{0.5} \mathrm{TiO}_{3}-\mathrm{BaTiO}_{3}-\mathrm{Na}_{0.5} \mathrm{Bi}_{0.5} \mathrm{TiO}_{3}$ piezoelectric materials. Sci Rep 2015, 5: 85-95.

[42] Yan F, Huang KW, Jiang T, et al. Significantly enhanced energy storage density and efficiency of BNT-based perovskite ceramics via A-site defect engineering. Energy Storage Mater 2020, 30: $392-400$.

[43] Jain A, Wang YG, Guo H. Microstructure induced ultra-high energy storage density coupled with rapid discharge properties in lead-free $\mathrm{Ba}_{0.9} \mathrm{Ca}_{0.1} \mathrm{Ti}_{0.9} \mathrm{Zr}_{0.1} \mathrm{O}_{3}-\mathrm{SrNb}_{2} \mathrm{O}_{6}$ ceramics. Ceram Int 2021, 47: 487-499.

[44] Li F, Zhai J, Shen B, et al. Simultaneously high-energy storage density and responsivity in quasi-hysteresis-free $\quad$ Mn-doped $\quad \mathrm{Bi}_{0.5} \mathrm{Na}_{0.5} \mathrm{TiO}_{3}-\mathrm{BaTiO}_{3}-\left(\mathrm{Sr}_{0.7} \mathrm{Bi}_{0.2} \square_{0.1}\right) \mathrm{TiO}_{3}$ ergodic relaxor ceramics. Mater Res Lett 2018, 6: 345-352.

[45] Qu B, Du H, Yang Z. Lead-free relaxor ferroelectric ceramics with high optical transparency and energy storage ability. J Mater Chem C 2016, 4: 1795-1803. 


\section{Captures}

Fig.1 X-ray diffraction patterns of NBT-ST- $x$ Mn ceramics (a) $20-80^{\circ}$, (b) $45-48^{\circ}$

Fig.2 Surface morphologies of NBT-ST- $x$ Mn ceramics (a) $x=0.0 \%$, (b) $x=0.5 \%$, (c) $x=1.0 \%$, (d) $x=1.5 \%$

Fig.3 (a)-(d) Temperature dependent of dielectric constant and dielectric loss, (e) $T_{\mathrm{m}}$ value and the maximum value of $\varepsilon_{\mathrm{r}}$ and (f) plots of $\ln \left(1 / \varepsilon_{\mathrm{r}}-1 / \varepsilon_{\max }\right)$ versus $\ln \left(T-T_{\max }\right)$ of NBT-ST- $x$ Mn ceramics

Fig.4 Electric-field-induced polarization and strain of NBT-ST- $x$ Mn ceramics (a) $x=0.0 \%$, (b) $x=0.5 \%$, (c) $x=1.0 \%$, (d) $x=1.5 \%$

Fig.5 Strain values and strain hysteresis as a function of doping content for NBT-ST- $x$ Mn ceramics

Fig.6 Strain as function of $P^{2}$ of NBT-ST- $x$ Mn ceramics (a) $x=0.0 \%$, (b) $x=0.5 \%$, (c) $x=1.0 \%$, (d) $x=1.5 \%$

Fig. 7 The unipolar $P-E$ loop as a function of electric field for NBT-ST- $x$ Mn ceramics (a) $x=0.0 \%$, (b) $x=0.5 \%$, (c) $x=1.0 \%$, (d) $x=1.5 \%$

Fig. 8 Energy storage performance of NBT-ST- $x$ Mn ceramics under different electric fields (a) recoverable energy density $W_{\text {rec }}$, (b) the energy loss density $W_{\text {loss. }}$ The the inset is energy storage efficiency $\eta$

Fig. 9 (a) Weibull distribution and the fitting lines of BDS (b) unipolar $P-E$ loops measured at their critical BDS (c) variation of $P_{\max }-P_{\mathrm{r}}$ value and (d) $W_{\mathrm{rec}}, W_{\text {loss }}$ and $\eta$ of NBT-ST- $x$ Mn ceramics 
Figures
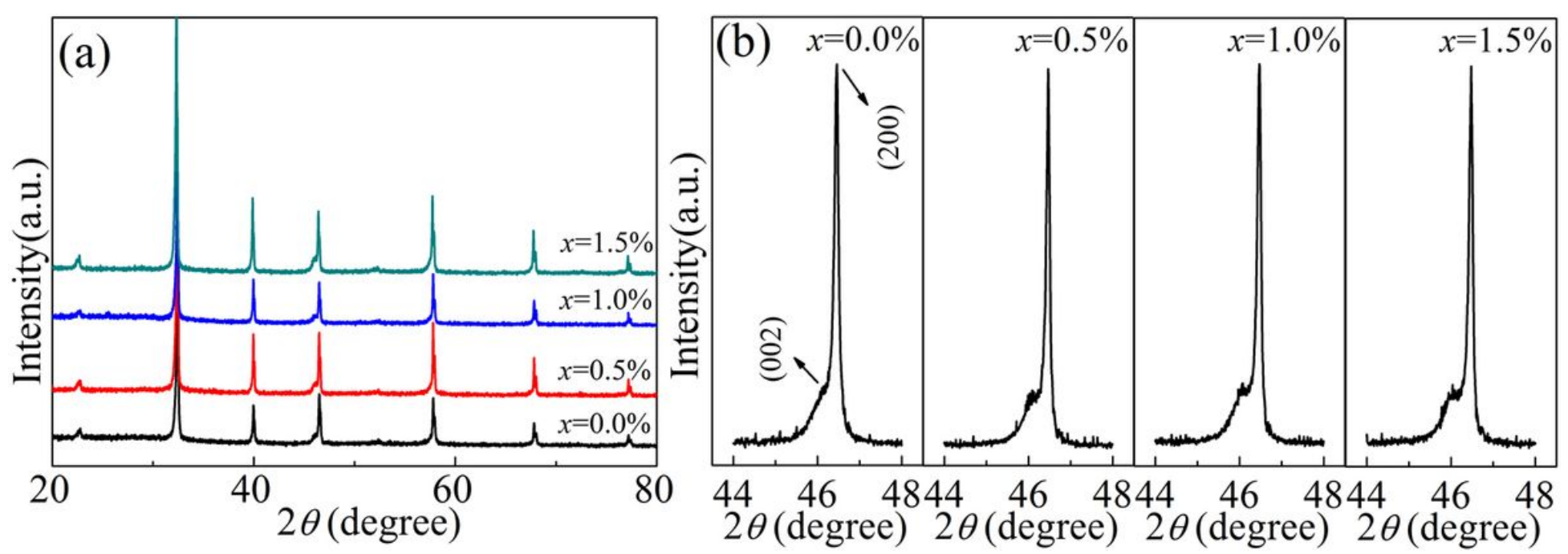

Figure 1

X-ray diffraction patterns of NBT-ST-xMn ceramics (a) 20-80o, (b) 45-48o 

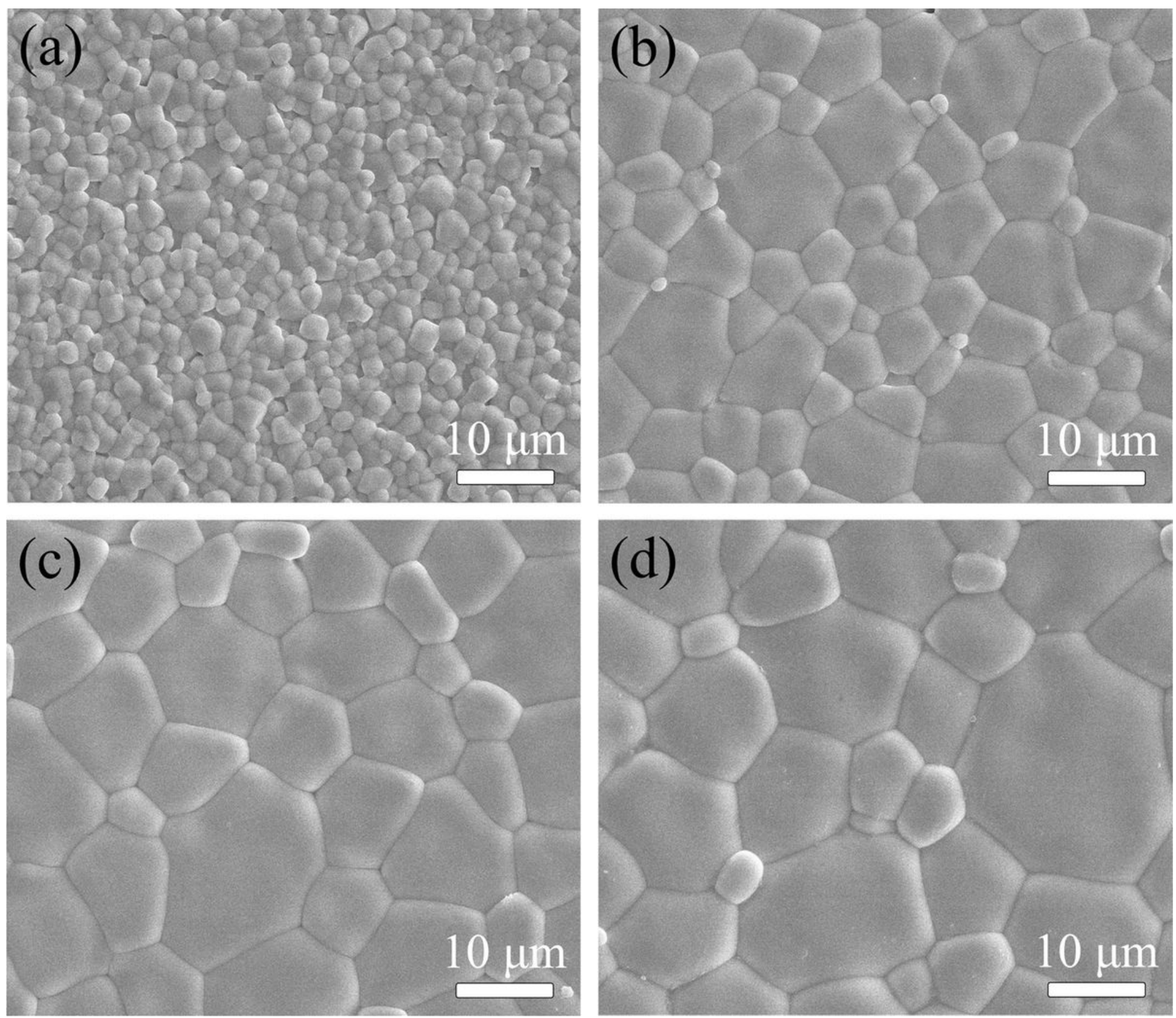

Figure 2

Surface morphologies of NBT-ST-xMn ceramics (a) $x=0.0 \%$, (b) $x=0.5 \%$, (c) $x=1.0 \%$, (d) $x=1.5 \%$ 


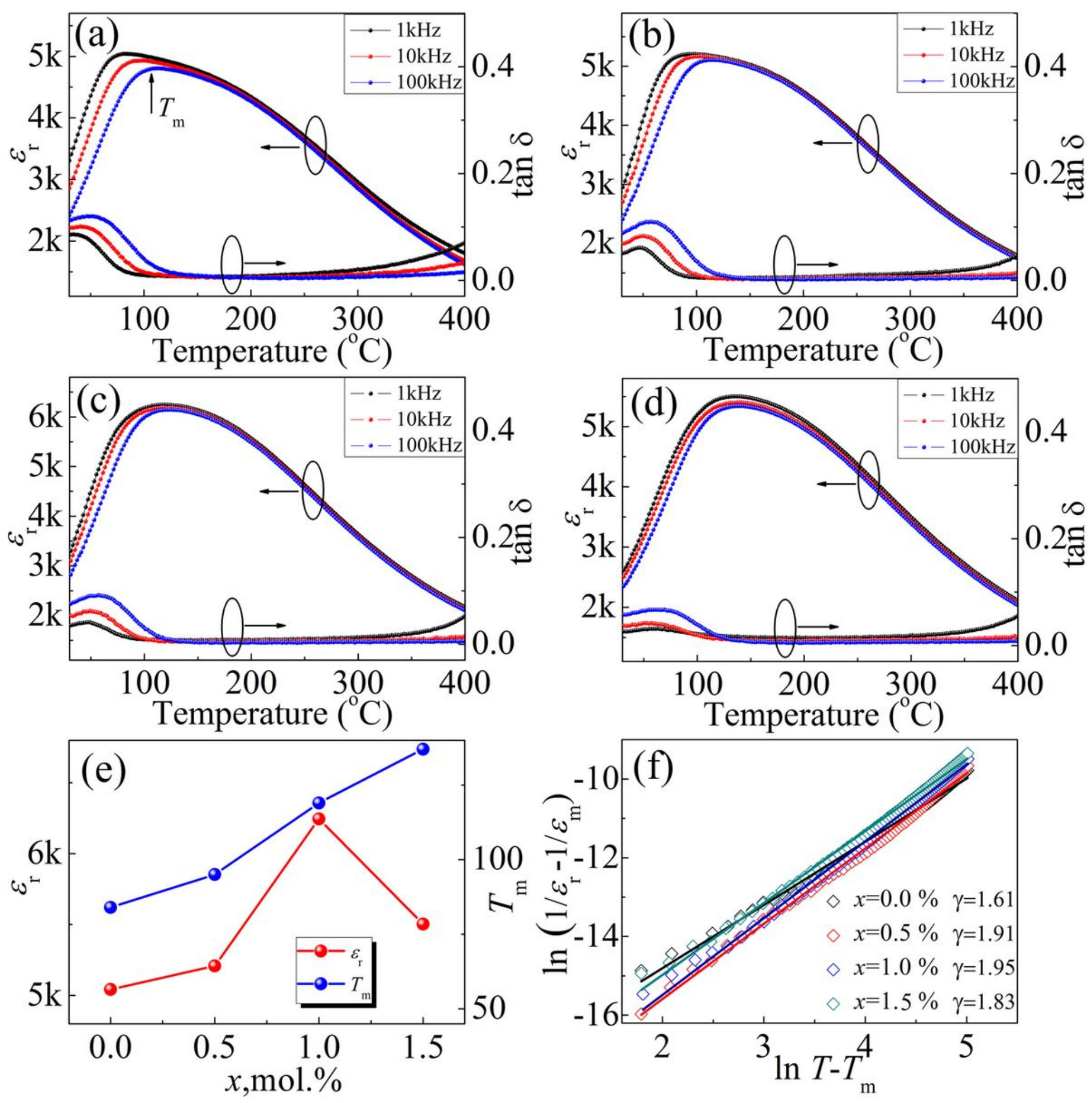

Figure 3

(a)-(d) Temperature dependent of dielectric constant and dielectric loss, (e) Tm value and the maximum value of $\varepsilon r$ and (f) plots of $\ln (1 / \varepsilon r-1 / \varepsilon \max )$ versus $\ln (T-T m a x)$ of NBT-ST-xMn ceramics 

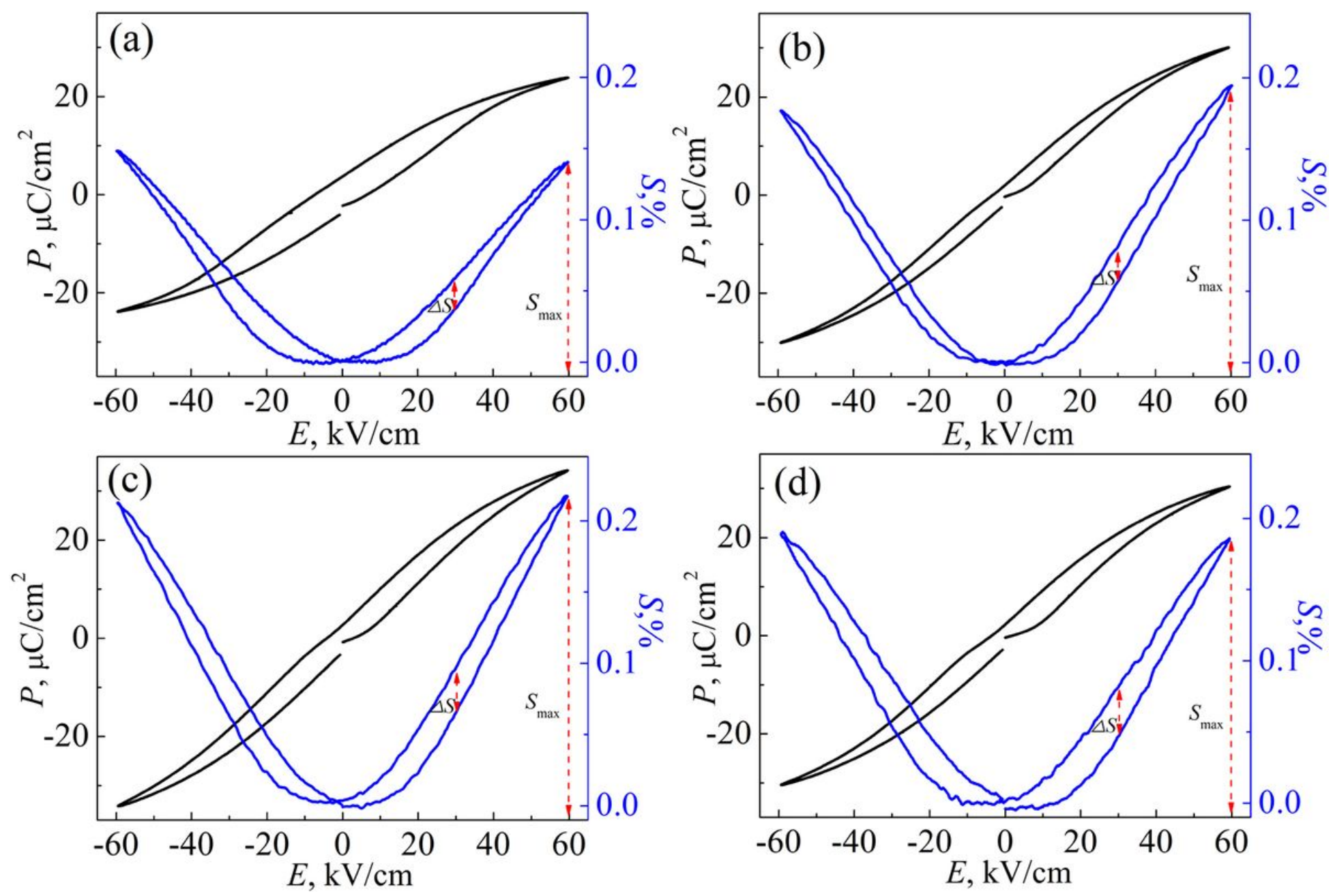

Figure 4

Electric-field-induced polarization and strain of NBT-ST-xMn ceramics (a) $x=0.0 \%$, (b) $x=0.5 \%$, (c) $x=1.0 \%$, (d) $x=1.5 \%$
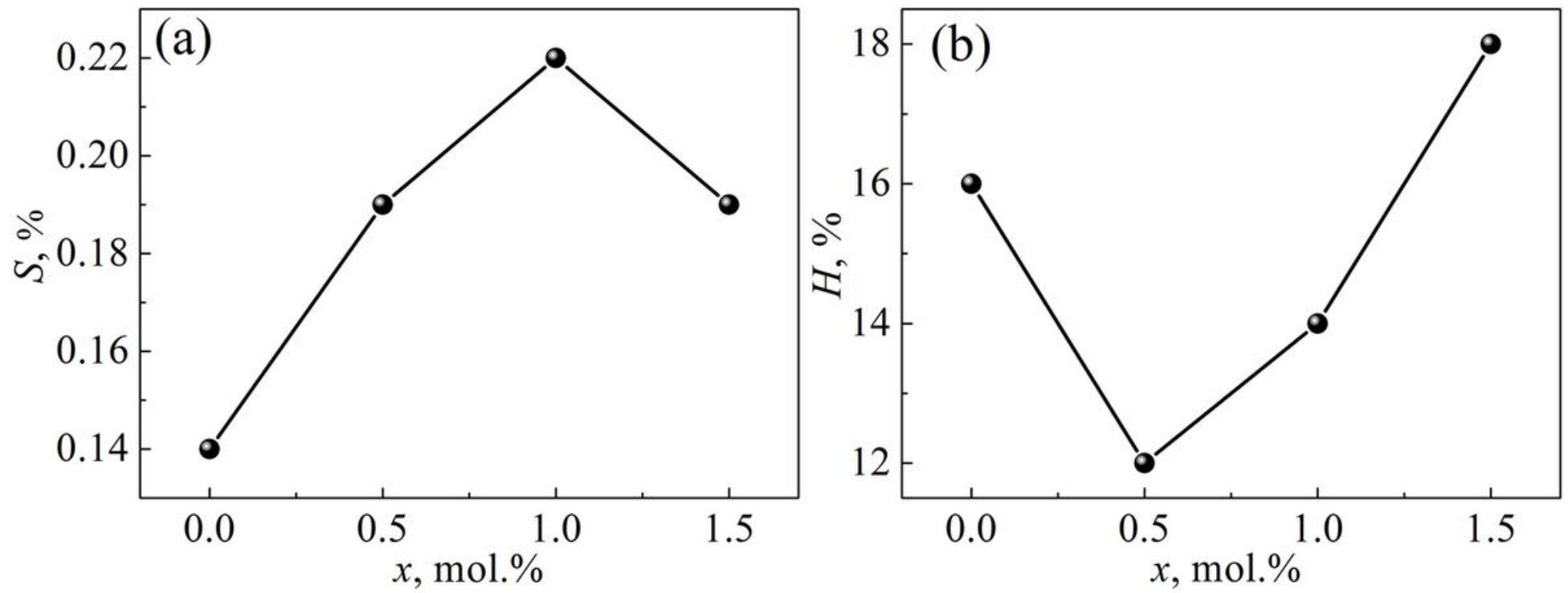

Figure 5 
Strain values and strain hysteresis as a function of doping content for NBT-ST-xMn ceramics
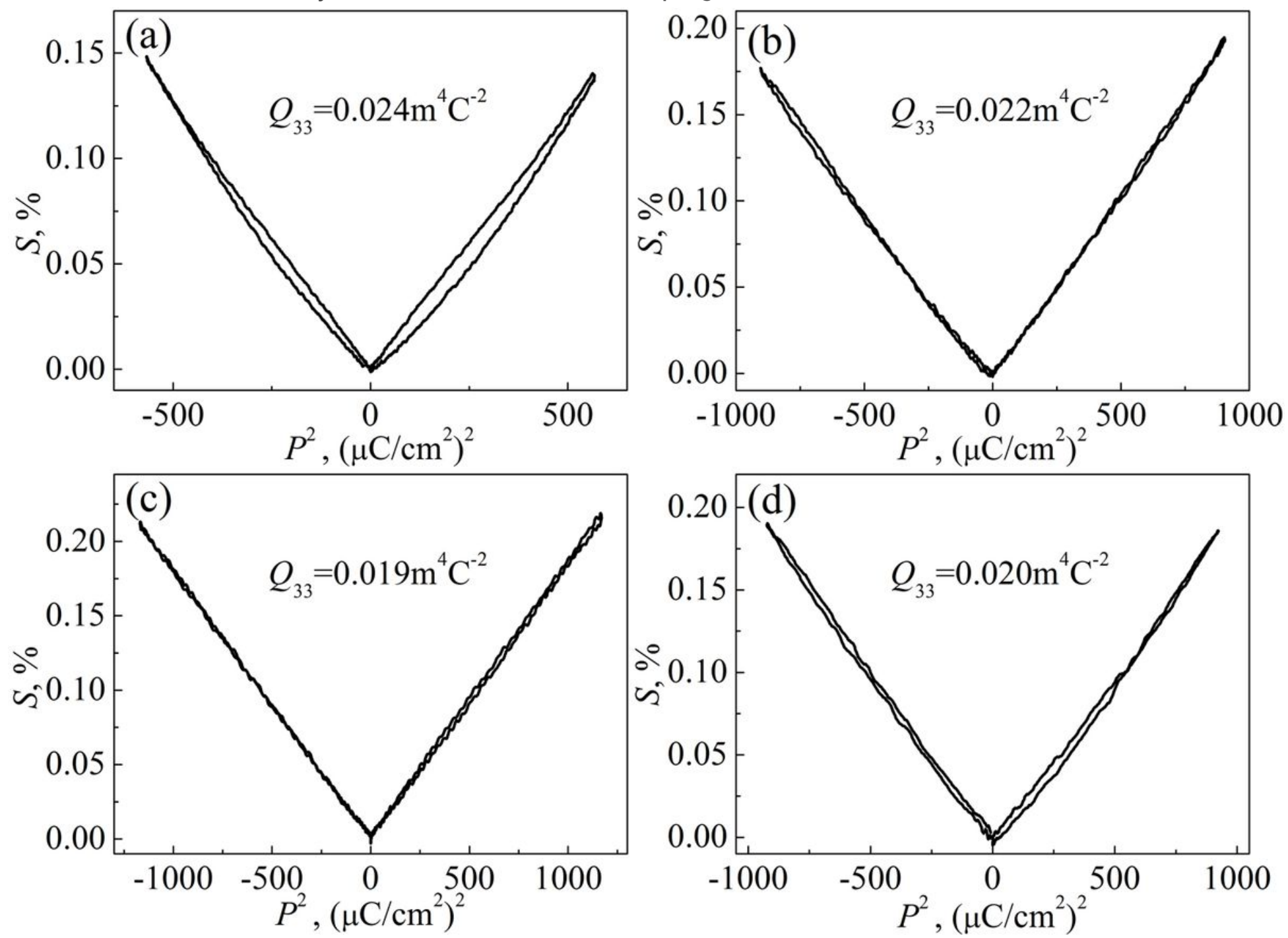

Figure 6

Strain as function of P2 of NBT-ST-xMn ceramics (a) $x=0.0 \%$, (b) $x=0.5 \%$, (c) $x=1.0 \%$, (d) $x=1.5 \%$ 

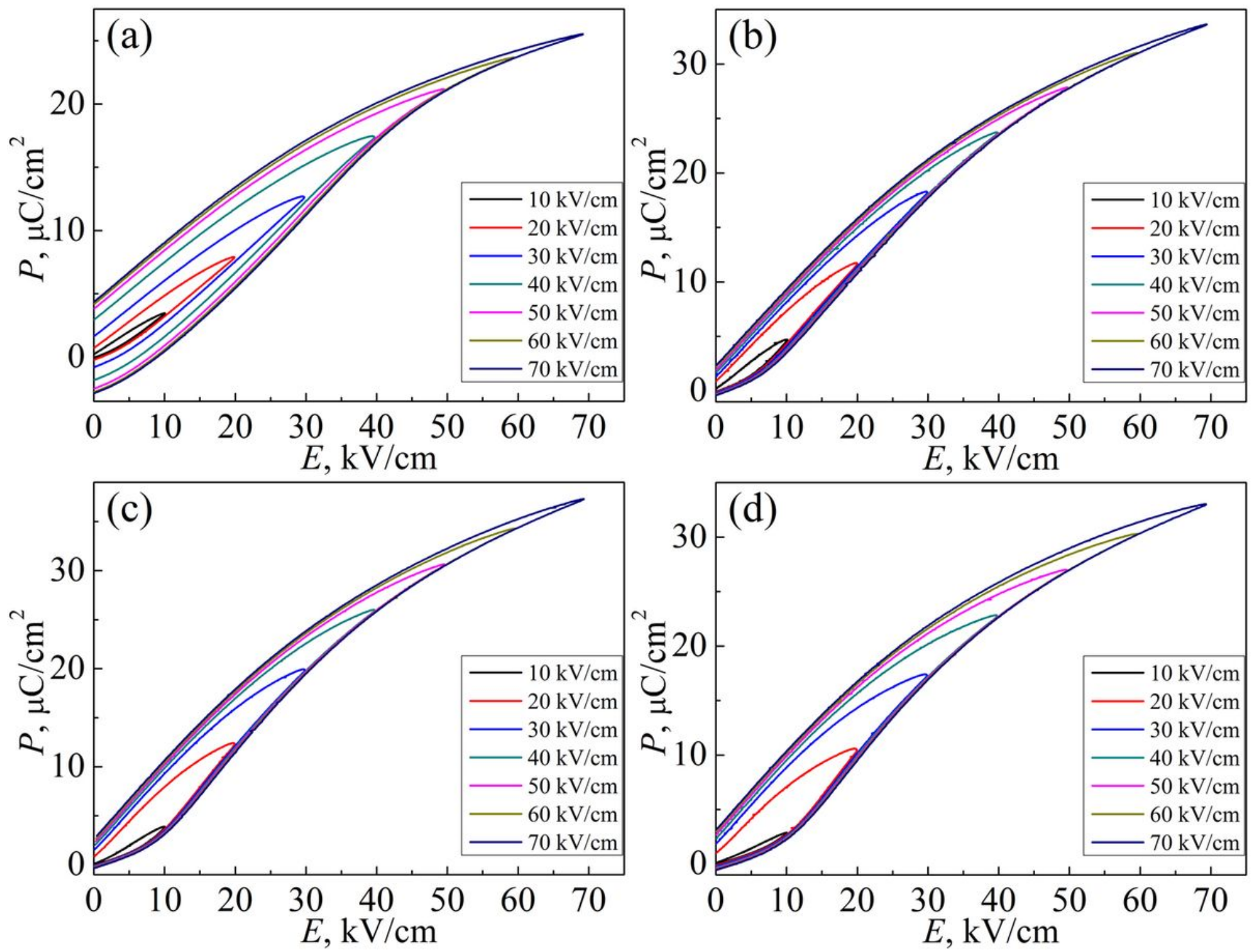

Figure 7

The unipolar P-E loop as a function of electric field for NBT-ST-xMn ceramics (a) $x=0.0 \%$, (b) $x=0.5 \%$, (c) $x=1.0 \%$, (d) $x=1.5 \%$
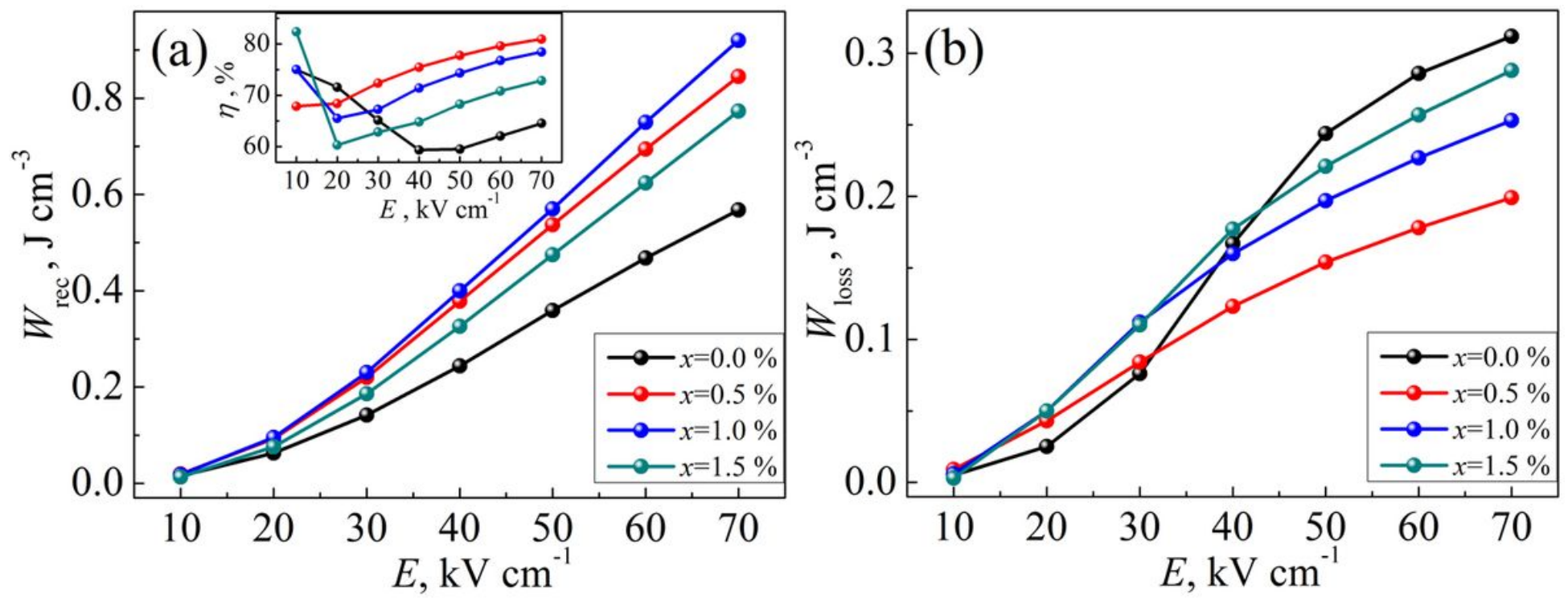
Figure 8

Energy storage performance of NBT-ST-xMn ceramics under different electric fields (a) recoverable energy density Wrec, (b) the energy loss density Wloss. The the inset is energy storage efficiency $\eta$
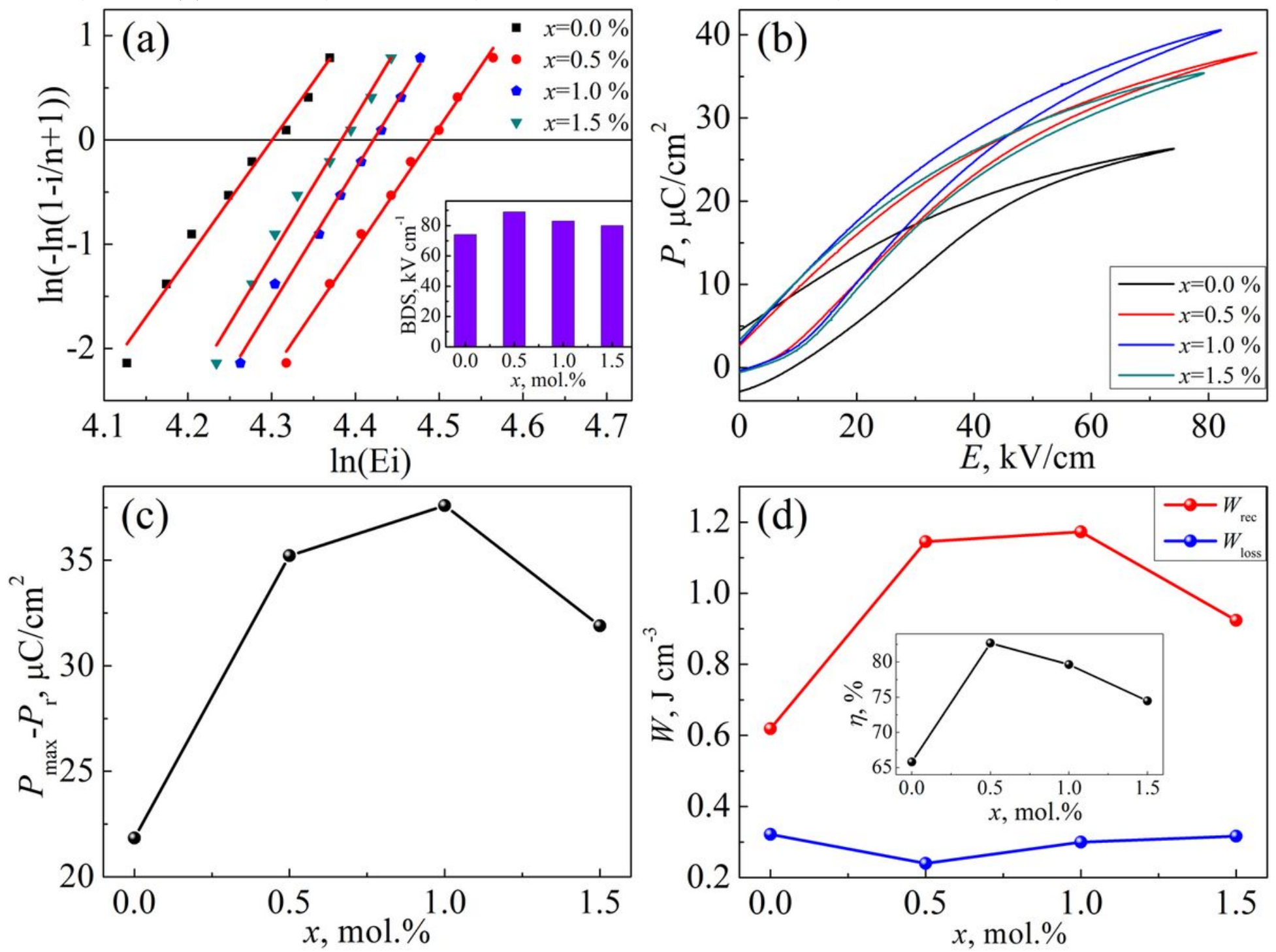

Figure 9

(a) Weibull distribution and the fitting lines of BDS (b) unipolar P-E loops measured at their critical BDS

(c) variation of Pmax-Pr value and (d) Wrec, Wloss and $\eta$ of NBT-ST-xMn ceramics 